Diánoia, vol. 32, no. 32, 1986

\title{
EL SUICIDIO COMO PROBLEMA FILOSÓFICO
}

JuAn A. Nuño

Universidad Central de Venezuela

Cuatro años antes de su muerte, es decir en 1889, Guy de Maupassant publicó otro cuento de escándalo. Se trataba de L'endormeuse, que se ha traducido bastante desacertadamente por "La dormilona". Alli se relata el sueño que tiene alguien, una hermosa mañana de verano, en el campo a orillas del Sena, justo después de leer un artículo de prensa sobre las estadísticas de suicidios. Sueña que en París existe una "Institución de la muerte voluntaria" en la que "se mata con limpieza y suavidad, agradablemente" a todo el que, por una razón u otra, desea morir. Es un club ameno y entretenido; lo mismo puede irse a él para elegir la muerte que para hacer lo que habitualmente se hace en cualquier club respetable: charlar, pasar el rato, y mientras se espera el momento en que se decide la muerte propia, apenas matar el tiempo. El modus operandi es sencillo y confortable: una cómoda tumbona (ésa es la famosa endormeuse o dormidera), en la que, rodeado de flores y deleitado por el perfume de su gusto, el candidato a la muerte voluntaria recibe los vapores de un gas inodoro; se supone que muere por lenta e imperceptible asfixia. Antes de comprobarlo, el protagonista del cuento de Maupassant despierta de tan premonitorio y optimista sueño.

Sin ánimo de exigir similar coherencia a todos los escritores, no estará de más recordar que Maupassant intentó suicidarse y murió, tras larga agonía, a consecuencia de las heridas infligidas, quizás añorando su imaginaria y rápida endormeuse.

A fin de evitar enojosas querellas competitivas, también conviene señalar que el club o institución de la muerte voluntaria con que generosamente quiso dotar Maupassant a París a finales del pasado siglo, nada tiene que ver con el terrible club de los suicidas de Robert Louis Stevenson, envuelto más bien en un halo de crimen organizado so pretexto de facilitar el acceso a "la puerta de escape de la muerte" de quienes por cualquier desesperado motivo la buscaban. Por el contrario, la civilizada oferta de Maupassant parece haber inspirado el mecanismo de eliminación 'física descrito por la película Soylent Green, que en el mun- 
do hispánico recibiera el amenazador título de Cuando el destino nos alcance. En lo fundamental, menester es reconocer que Maupassant se adelantó, al menos en teoría, a las proposiciones y métodos que ciertas sociedades contemporáneas, como por ejemplo la inglesa Exit, ofrecen a sus miembros. Hasta el procedimiento elegido (gas adormecedor) viene a coincidir con el que los manuales de Exit recomiendan como muerte menos traumática.

En cualquier caso, el cuento de Maupassant es revelador de la gran ambigüedad que preside el terrible tema del suicidio. Por un lado, el rechazo, ya que lo que desencadena el sueño del protagonista es su repulsa ante la noticia y detalle de tanto suicidio en el mundo; por otro, el atractivo morboso de la muerte voluntaria atenuado por las facilidades de ejecución; en el fondo, el respeto a la libre voluntad del ser humano que, llevado al límite, ha de permitir la suprema decisión de terminar con la vida cuando se desee. Y presidiendo el conjunto, la justificación biológica del suicịdio expresada por Maupassant en términos nada originales desde los remotos estoicos:

¡El suicidio! Pero jsi es la fuerza de quienes ya no tienen nada, es la esperanza de quienes ya no creen, es el sublime valor de los vencidos! Sí: hay una puerta por lo menos en esta vida; siempre podemos abrirla y pasar al otro lado. La naturaleza ha tenido un movimiento de piedad; no nos ha aprisionado. ¡Gracias en nombre de los desesperados!

Cualquier reflexión sobre el suicidio ha de partir de semejante ambigüedad: a la vez, rechazo y fascinación; condena y aceptación; huida y recurrencia. De lo que se trata es de trascender la ambigüedad, de superar la aparente contradicción. $\mathrm{Ni}$ represión ni estímulo; bastaría con pretender alcanzar cierto grado de comprensión del suicidio.

Sin caer en un tedioso resumen histórico, pueden invocarse ciertas figuras consagradas dentro del nutrido mundo de los suicidas. Son los suicidios emblemáticos.

Desde luego, Sócrates, prototipo occidental de la muerte voluntaria quizás más por razones políticas que filosóficas, pero en todo caso, ilusionado con la creencia intelectual de alcanzar tras la muerte el conocimiento perfecto de las Ideas o Arquetipos.

Pero también los inevitables suicidas amorosos representados para siempre por la pareja de Verona, modelo de suicidas jóvenes, precipitados e inconscientes.

El paradigma de los suicidas por despecho y sed de venganza es proporcionado por la cruel Medea, implacable en su afán de desquite. En 
cuanto al joven Werther inaugura la línea de los suicidios románticos de los que tan copiosa cosecha recogería el siglo xIx.

Los kamikazes japoneses o los 960 defensores judíos de Masada o los miles de mártires cristianos o el checo Jan Pallach o los bonzos no sólo de Vietnam o los comunistas confesos y arrepentidos de los procesos de Moscú y similares, representan al tipo de suicida heroico que busca la muerte por motivos religiosos o ideológicos y pretende casi siempre dar ejemplo con su deliberado sacrificio.

Jaime Torres Bodet, Montheriant, Hemingway y, más recientemente, Koestler significarían el parangón de suicida terminal, o por vejez o por enfermedad o por hastío de vivir. Parece ser que en vista de las nuevas técnicas de sobrevivencia clínica, se trata del modelo de suicida que más se va a llevar en la próxima temporada, pues, como nadie ignora, esto del suicidio también está regido por la moda y sometido al efecto del contagio social.

La inmediata lección que se desprende de tan sucinto repaso a las grandes figuras arquetípicas del suicidio es que predomina la diversidad: no es posible hablar del suicidio, sino de la pluralidad de suicidas $y$, en el mejor de los casos, agruparlos por categorías. Es justamente lo que hizo quien estudió, por vez primera científicamente el suicidio, el francés Durkheim, con la ventaja simplificadora de que sólo distinguió, como es bien sabido, tres tipos o modelos de suicidas. Pero hay otra lección quizás menos obvia, si bien más fundamental: la de que el suicidio es un hecho, una realidad sustantiva, algo que no puede suprimirse; no es un accidente o forma de civilización. Como la sombra acompaña al cuerpo ante la luz, el suicidio escolta al ser humano como una permanente posibilidad; forma parte de la naturaleza no sólo humana, sino animal, pues conocidos son los múltiples casos de especies animales que cometen suicidios en tanto tales especies (casos de ballenas o de lemures) o en tanto individuos (como pasa con los perros o con ciertos animales salvajes en cautiverio). El hombre tampoco escapa al ejercicio del recurso de una dotación que le puede impulsar a destruirse dadas ciertas condiciones. Tan sólo a partir de la aceptación del suicidio como dato inamovible será posible desarrollar una estrategia inteligente para enfrentarse a tan sustantiva realidad.

La constatación del suicidio determina mecánicamente el par de opuestos consagrados: su rechazo y su aceptación. Ha habido momentos en la historia de la humanidad en que colectivamente se ha aceptado el suicidio y no sólo como idea. El fin del Imperio Romano fue una de esas épocas de aceptación y aun estimulación del suicidio: los estoicos, por un lado, y los cristianos, por otro, hicieron todo lo posible por competir en una atroz carrera por aumentar el número de suicidas, si 
bien con distintos procedimientos y por razones diferentes. Én la actualidad, no sólo los fanáticos de cualquier Jomeiny se suicidan a racimos debidamente condicionados y alentados, sino que cualquier emocionado slogan del tipo "patria o muerte" contiene un llamado al suicidio y, desde luego, la correspondiente aprobación y aplauso de quienes comulgan con el credo propulsor. Sobran, en general, los documentos aprobatorios o incitadores al suicidio. Uno de los más conocidos y citados es el de Séneca, también consecuente con su propia prédica:

Necio, ¿de qué te quejas, a qué temes? Doquiera que mires hay un fin a tus males. ¿No ves ese hondo precipicio? Lleva a la libertad. ¿Contemplas la corriente, el río, el pozo? La libertad se alberga en ellos. ¿Puedes ver ese árbol retorcido y doblado? De cada una de sus ramas cuelga la libertad. Tu cuello, tu garganta, tu corazón son otras tantas vias de escape de la esclavitud. ¿Preguntas por el camino de la liberación? Lo encontrarás en cada vena de tu cuerpo...

Como prueba de la condición cíclica, repetitiva que caracteriza al espíritu humano en sus productos históricos, doce siglos más tarde, el señor de Montaigne casi acude a los mismos alegatos:

La muerte es la cura de todo mal. Trátase de un puerto seguro al que jamás hay que temer y con frecuencia, buscar. Todo se reduce a que el hombre ponga fin a sus días o a que sufra la muerte; 0 adelanta su hora o la espera. Sea como fuere, siempre será la suya; por donde se rompa el hilo, todo termina, pues se llega al final del recorrido. Cuanto más voluntaria la muerte, más bella será. La vida depende de la voluntad ajena; la muerte, de la nuestra.

(Coûtume de l'île de Céa)

No había pasado mucho tiempo sin que el escocés Hume se atreviera a dar el paso siguiente: reducir la importancia de la vida humana a su justo nivel biológico:

¿Tanta importancia posee la vida humana que tiénese por insolencia contra la humana prudencia el disponer de ella? Pero la vida de un hombre no presenta más importancia para el universo que la vida de una ostra...

Si disponer de la vida humana fuera tan específica responsabilidad del Todopoderoso que resultaría una atentado contra su derecho el que los hombres dispusieran de las suyas propias, tan criminal sería procurar preservarla como querer destruirla... Por lo tanto, si me avalanzo sobre la espada, también recibiré la muerte de manos de 
la divinidad, lo mismo que si aquella procediera de un león, de un precipicio o de unas calenturas...

La moderna superstición europea considera impío poner punto final a nuestra propia vida por rebelarnos contra el Creador. Pero, agrego por mi parte, ¿por qué no sería igualmente impío levantar casas, cultivar el suelo o hacerse a la mar?

(Essay III: On suicide)

Por supuesto que entre unos y otros se dan matices significativos, pero el principio es común: se acepta el suicidio, se justifica y, en algunos casos, se propone franca y abiertamente. Forman parte de una civilización dispendiosa disfrazada de tolerante; o, si se prefiere, a la inversa, una civilización de tolerancia que se permite el derroche de vidas humanas. Eso sí: jamás en silencio; el suicidio, ante todo y en cualquier época, es un acto locuaz. $O$ habla el suicida (la paradigmática carta) o se habla del suicidio. Podrá ser un acto natural, pero no indiferente. El suicidio inquieta. Como inquieta la muerte, su ocasional desenlace. Casi siempre esa inquietud se ha traducido en explícito rechazo. Se procede a condenar y aun a perseguir el suicidio. Sabido es que se les negaba, y en algunos sitios aún se les niega a los suicidas, la sepultura ordinaria; la familia caía en la más abyecta infamia y alguien, el rey, el municipio o el Estado, disponía de sus bienes. De aquí, el recurso justificativo de la locura; era preferible declararlo demente para salvarlo post-mortem del envilecimiento y ahorrar a sus deudos tan enojosas consecuencias. De tal manera que los primeros casos registrados de trastorno conductual fueron más producto de la compasión y la trampa juridica que efecto de algún examen clínico. La locura como paliativo, no como diagnóstico. No han cambiado mucho las cosas; si acaso, se han refinado los mecanismos de hipocresía; las grandes religiones siguen condenando al suicida y negándole o dificultándole el reposo definitivo; la sociedad sigue reprobando el acto que afecta por contaminación a los familiares; y ciertas instituciones, bancos, compañías de seguros, obstaculizan el acceso a sus bienes o definitivamente los niegan. Si antes se ha hablado de formas de civilización dispendiosas, menester será calificar a esta otra de parsimoniosa y egoísta y, en consecuencia, abiertamente intolerante. Desde la Revolución Francesa, vivimos obsesionados por el fetiche de los derechos humanos, pero ciertamente entre ellos no se inscriben los del suicida: el hombre tiene derecho a muchas cosas entre las cuales no está el derecho a abandonar esta vida cuando le plazca o convenga. Lo que prueba el principio de compromiso moral que rodea al suicidio: imposible la indiferencia. $O$ se acepta hasta la 
justificación más exaltada o se rechaza hasta la implacable persecución. $\mathrm{O}$, en forma atenuada, se propone su prevención.

No sólo se da la diversidad de suicidios o tipos de suicidios, sino que es necesario marcar fronteras entre lo que es el suicidio directo y explícito (la habitación cerrada, la cabeza dentro del horno de gas, la nota sobre la mesa) y lo que constituye la variedad de suicidios vergonzantes, disfrazados casi siempre de hábitos nocivos (fumar, consumir drogas), de accidentes (conducir a elevada velocidad) o de política pacifista (acumular armas termonucleares). Lo que lleva a considerar la diferencia que hay entre el suicidio del individuo (que, por lo general, es el que preocupa al especialista práctico) y el de la especie, cuya posibilidad aumenta alarmantemente. Esto es, hay diferencia entre un suicidio inmediato y otro diferido: o suicidio evidente y suicidio disfrazado. Por algo, en vista de las variaciones de significado y de la riqueza del tema, existe ya en determinadas instituciones superiores la especialidad de la "suicidiología".

En principio, cualquier explicación colectiva del fenómeno del suicidio le corresponde a la sociología, que además de registrarlo cuantitativamente, observa sus variaciones en periodos de tiempo y trata de establecer determinados factores de incidencia. Las explicaciones individuales son propias de la literatura (desde Shakespeare a Dostoievski) y de la psicología, así sean tan incompletas e insuficientes como la de Freud.

Si hubiera necesidad de justificar cualquier intento de explicación bastaría con invocar la ignorancia deliberada que se mantiene en torno al tema prácticamente tabú del suicidio. Una buena prueba de esa ignorancia, larga de siglos, es la niebla de los prejuicios que envuelve cada suicidio. Otro de esos dobles expertos en el tema (por haberlo intentado y por haberlo estudiado), el británico Álvarez, ha llegado a contar hasta seis grandes falacias sobre el suicidio en su revelador libro The Savage God. A Theory of Suicide.

Hay, ante todo, la falacia de que el suicidio es propio de los jóvenes ènamorados; también la falsa explicación del suicidio como juego, lo que haría que muchos incurrirían en su propia muerte por error, como quien se equivoca al sumar. Se ha sostenido además que el suicidio es una consecuencia directa del mal tiempo, de los meses de invierno, cuando la verdad sociológica es que la curva sube en la entrada del verano; se ha atribuido asimismo a una suerte de costumbre nacional, achacándoselo mayoritariamente a los nórdicos, cuando las cifras lo desmienten colocándolo más bien como de mayor popularidad hacia Centro Europa, sin que ello signifique que los datos sean constantes; se lo ha querido relacionar con el alto grado de desarrollo industrial y en especial con 
el aumento de bienestar debido a la protección estatal, cuando se ha podido registrar las mismas cifras, sin variación significativa, antes y después de aplicar los mecanismos de seguridad social propios de cualquier Welfare State; se parte del axioma de que quienes lo pregonan no lo hacen, cuando más bien están advirtiendo y hasta emitiendo señales de socorro. $Y$ por último, se dice con toda seriedad que quienes lo han intentado y fallado, nunca reincidirán: la triste realidad estadística es que tienen tres veces más probabilidades de repetirlo que quienes jamás lo intentaron.

Como aquellos animales de la famosa granja, todos los suicidios son iguales, pero unos son más iguales (esto es, más legales y aceptados) que otros.

En el caso de los mártires cristianos se dispone de un excelente laboratorio comparativo a fin de establecer la mencionada condición de relatividad valorativa. Conocida es la exaltación ideológica que hizo de sus mártires el cristianismo en los primeros tiempos, fueran aquéllos tantos como la Iglesia pretende o algo menos. El hecho histórico es que los buenos cristianos buscaban su muerte en cualquier ocasión. Revelador es el lamento que ha quedado de un infeliz procónsul romano en Africa, asediado por una muchedumbre clamante de cristianos en busca del martirio: "Marchad a colgaros" - tuvo que decirles_- "o a ahogaros vosotros mismos y dejad tranquilo al magistrado de Roma." Tertuliano, quien se hizo tristemente célebre por creer el absurdo, ordenaba a los cristianos no abandonar las ciudades en que se les perseguía a fin de incrementar así el número de mártires; donde puede verse, entre otras cosas, que los movimientos revolucionarios no han inventado nada. Para ese mismo Tertuliano, la propia muerte de Cristo era un suicidio explícito y glorioso. Suicidarse era la forma más rápida de asegurar la salvación eterna y, de paso, ayudar al establecimiento del poder político de la naciente Iglesia. De modo que, tan pronto fue alcanzado este objetivo, cambió la valoración de esa clase de suicidio disfrazado de sacrificio. Lo sabemos por la condena sin paliativos a la secta de los donatistas, cuya ansia de martirio fue tan desenfrenada y sobre todo tan poco productiva que la Iglesia no vaciló en declararlos herejes. Abordaban inclusive a las gentes en calles y caminos pidiéndoles que los mataran, bajo la amenaza de devolverles el servicio si no accedían a su patético ruego; llegaron a anunciar su muerte pública, acompañados de familiares, para convertirlo en edificante espectáculo. Bien visto, no eran sino la consecuencia extrema de tanto martirologio. Pero como ya habian cambiado viento y condiciones, fueron condenados y con ellos, el suicidio, en tanto forma de manifestar expeditivamente la fe. Lo que en un tiempo había sido orgullo de la Iglesia, desde San Agustín se convirtió en oprobio y 
escándalo del buen cristiano. La misma puerta generosamente abierta se cerró de golpe y porrazo, impidiendo el acceso al Paraíso de los mártires fuera de época, que pasaron a ser vulgares suicidas, a los que hasta la sepultura se negara. En el siglo xI, San Bruno ya había acuñado la fórmula que marca la inversión valorativa total: llamó a los suicidas "mártires de Satanás".

La lección no puede ser más breve: el suicidio es aprobado unas veces, condenado otras. Cuando se trata de Masada o de protestar por la ocupación soviética o de beber la cicuta ante los injustos jueces o de hundirse caballerosamente con su barco, el suicidio asume la forma de la heroicidad más celebrada. De Séneca a Allende se venera el valor de quien acepta y aun busca la muerte.

Con lo que el suicidio prueba una vez más su lógica pertenencia al género supremo de la muerte. Como ésta, una vez se prohíbe y es pecado, y otra se impone y premia. No matarás, salvo en la guerra o si te nombran juez o verdugo. De modo que cualquier juicio sobre el suicidio, como en general sobre cualquier acción homicida, es convencional y arbitrario, dependiendo de las conveniencias sociales y de las circunstancias históricas. La misma religión que orgullosamente invoca a sus primitivos mártires condena horrorizada el suicidio masivo de aquella secta cristiana en Guyana a finales del 78 o mata a los supervivientes de la secta de los albigenses por haber propuesto exactamente lo mismo que hicieron ante los leones los primeros cristianos.

Esa misma relatividad que así se manifiesta prueba la función social que desempeña todo suicidio. Al igual que el aborto, será un crimen contra la vida siempre que el propósito social sea el aumento de población. Pero allí en donde se llega al exceso demográfico que aconseja ese crecimiento púdicamente llamado "cero", comienzan a borrarse las fronteras de las prohibiciones y a cambiar las valoraciones; no sería imposible que, de seguir la explosión demográfica de la humanidad y de no acudir antes al viejo y eficaz recurso de la sangría ocasional de la guerra, se alcanzara la promoción organizada del suicidio, quizás bajo la amable forma de los clubes de muerte voluntaria previstos por Maupassant. En el dominio de la ciencia-ficción se da un paso más y se le presenta compulsivo, como puede apreciarse en el Mundo feliz de Huxley o en This perfect day de Ira Levin. Mientras llega, vuelve a repetirse aun tímidamente cierta permisividad, al estilo de la practicada en los tiempos tardíos del Imperio Romano. Así como en las ciudades importantes de ese Imperio, el Praeceptor contaba con una reserva suficiente de cicuta a disposición de quienes la solicitaran, ahora en algunos países avanzadas han comenzado a aparecer las sociedades que ponen a disposición de sus miembros manuales sobre técnicas de suicidio. 
Para probar a contrario que, por mucho alcance social que posea, el suicidio como toda muerte es siempre un acto individual, basta con atender a la condena y persecución que de él se hace en las sociedades totalitarias. En aquel tolerante Imperio Romano, sólo los hombres libres, los plenos ciudadanos, podían disponer de su vida, pues ni los esclavos, que eran una simple mercancía, ni los soldados, que desempeñaban un servicio público, podían atentar contra su vida, por duras e insoportables que fueran las condiciones en que aquélla transcurriera. De hacerlo, los primeros atacaban a la sagrada institución de la propiedad privada, y los otros a la augusta propiedad del Estado. Por lo mismo, como el progreso es inexorable, todos los ciudadanos de cualquier país totalitario, sin exclusión, son propiedad del Estado: en la medida en que está prohibido dañar esa propiedad, está prohibido suicidarse, al menos de forma individual, a pesar de los nombres recalcitrantes de Mayakovski, Fadeyev y Haydée Santamaría.

Es decir: la gente se suicida igualmente en el Este como en el Oeste, con Dios y con el diablo. Es harto revelador que la Suecia de 1910, un país rural y atrasado, al nivel de los del actual Tercer Mundo, presentara la misma proporción de suicidas que la avanzada e industrializada Suecia de hoy; en contra de lo que creyeran los sociólogos positivistas o de lo que aún creen los sociólogos marxistas, el suicidio no es una consecuencia socio-económica. Lo que no excluye ni la posibilidad ni las ventajas de estudiarlo desde el punto de vista sociológico. Por lo general, lo más que se logra con tales estudios es reordenar los datos existentes, clasificar de una u otra manera el plural, complejo y relativo mundo del suicidio. Se ha llegado a distinguir entre suicidios lógicos (o terminales: cuando no hay otra salida: el enfermo de cáncer o el banquero arruinado), $t$ eológicos (impuestos por creencias o ideas o sentido del sacrificio o del honor personal), patológicos (la inmensa mayorfa, es decir, los que precisamente no pueden ser clasificados en las anteriores casillas), y hasta hereditarios, por aquello de que para agunos presenta rasgos que se conservan o transmiten generacionalmente. $Y$ aunque sea antigua y se halle, como suelen decir los optimistas, "superada", no estaría de más volver a echar un vistazo a la vieja y primera clasificación sociológica, la de Émile Durkheim. Sirve para darse cuenta de cómo todo intento colectivo de estudiar y comprender el suicidio lo único que logra es negar la acción individual, esto es, justamente aquello que caracteriza esencialmente al suicidio.

Ya se sabe que para Durkheim había tres posibles tipos de suicidas, el egoísta, el altruísta y el que denominó, con término tomado de Guyau, "anómico" (es decir, sin ley, desorganizado). Es egoísta quien se suicida por vivir demasiado separado del contexto social (fenómeno de la dis- 
persión familiar); altruísta quien lo hace, por el contrario, por estar demasiado pegado al grupo (propio de mártires y, en general, sociedades y comunidades primitivas, como grupos religiosos, militares y políticos). Por su parte, el suicida desorganizado o anómico es consecuencia de un cambio repentino del contexto social (súbita pobreza o súbita riqueza). No importa el detalle; lo que interesa es percatarse de cómo, para el sociólogo, el suicida es un efecto social, nunca un acto individual. Ciertamente que no existe el individuo aislado, en estado puro, y que, en consecuencia, todos sus actos, incluyendo el de la muerte voluntaria, se dan en un marco colectivo. Eso va a permitir entender al suicida en relación con el grupo, pero todavía quedaría por explicar el hecho singular, aislado, personal del suicidio. Es posible que a consecuencia de un súbito empobrecimiento o de un súbito enriquecimiento, un hombre decida matarse, pero como afortunadamente no todos los que se arruinan de un día para otro o se convierten en millonarios de la noche a la mañana se matan, la caracterización de Durkheim, que permite la clasificación elegante del suicidio bajo la etiqueta de la anomia o desorganización social o cualquier otra siempre de índole sociológica, no explica el suicidio real y efectivo, desde el momento en que sólo explica las condiciones generales, pero jamás el hecho mismo. Dicho de otro modo: la insuficiencia del planteamiento sociológico es evidente. Si bien es cierto (o puede concederse que lo sea) que todo banquero que se mata por una súbita ruina es un suicida anómico, la inversa no es verdad: no todo banquero empobrecido en 24 horas se suicida. La sociología ayuda a recoger y ordenar los cadáveres, pero aún queda por entender el hecho que los ha llevado a tan definitivo estado.

Hay una grave consecuencia ontológica de todo esto: al no depender el suicidio del marco social en que se presenta, subsiste como un dato inherente a la humana naturaleza. Como el sexo, el suicidio acompaña inexorablemente al hombre.

Revisadas las explicaciones sociológicas, queda abierto el camino para delinear los trazos elementales de una interpretación filosófica del suicidio.

Hay, cuando menos, dos ilustres precedentes, a cada cual más decepcionante: Freud y Camus.

La poca claridad de Freud sobre el tema del suicidio se combina con la variación que sus tesis originales experimentaron al agregar un nuevo principio de explicación del comportamiento humano, el famoso "instinto de la muerte". El resultado es que Freud llegó a explicar el suicidio como la consecuencia de un triple movimiento anímico. Primero, se ha de producir la introyección de algún ser querido desaparecido y llorado; luego, por efecto de la melancolía, ese otro que penetra en el doliente 
crece, lo divide y enfrenta como un Doppelgänger siempre insatisfecho, que hablara de muerte, en antitesis a la vital libido. El suicida se mata porque cierta voz interior e invasiva así se lo ordena, ganando en el enfrentamiento el principio tanático, desorganizativo o de entropía, que tiende a establecer la inercia de la materia inorgánica.

Aun dejando de lado todo cuanto de oscuro, esencialista y deus ex machina pueda tener el recurso a un misterioso segundo principio (tanatos contra libido), la explicación de Freud sólo se diferencia de la de Durkheim en el punto de partida, pero coincide con la de cualquier sociólogo en el mecanismo de llegada. Cierto que Freud se concentra en el individuo y no en el contexto social pero reduce el suicida a ser un pasivo objeto de fuerzas que, desde fuera, se apoderan de él. Además de traspasar la voluntad y aun responsabilidad del acto, se acude al mismo expediente determinista de Durkheim; en vez de ser el suicida juguete de las condiciones o cambios sociales, lo es de la división y consiguiente lucha que los instintos de vida y muerte desarrollan en su interior hasta que triunfa el de la destrucción. De tal manera que la explicación es menos individualista de lo que a primera vista parece, pues los principios (de placer, realidad y destrucción) trascienden al sujeto y convienen genéricamente a toda la humanidad. Por último, no deja de ser una explicación tan esquemática que en definitiva nada explica. Decir que el suicida se mata porque en él ha triunfado el instinto de la muerte es una manera poética de decir que se mata porque se mata. Aquella comparación que en una ocasión empleara Freud entre el amor y la autodestrucción, por cuanto ambos invaden y dominan a quien los padece, sirve para subrayar la condición impuesta de la explicación freudiana; han cambiado las palabras, pero se sigue explicando el suicidio (y el enamoramiento) por el recurso a algún demonio o potencia invasora que se apodera del alma del hombre.

Por su parte, Camus no decepciona con su explicación del suicidio (ya que no da ninguna), sino con su utilización filosófica. Primero promete mucho con aquello de que "sólo existe un problema filosófico verdaderamente serio, el suicidio"; para terminar frustrando tan prometedora declaración al emplear el suicidio para probar una tesis metafísica. Conocido es que para Camus la categoría del "absurdo" tenía aproximadamente la misma connotación metafísica que la de "contingente" para Sartre. La existencia humana es absurda, la vida es absurda y las acciones del hombre son absurdas, querían decir que eran todas contingentes, no esenciales, nada necesarias, gratuitas, montadas en el aire, sin el apoyo sustancial que, por ejemplo, tienen los seres esenciales y definitivos como las piedras o los números. Vivir existencialmente es aceptar el absurdo y, a partir de él, levantar cada hombre y cada época 
un sentido siempre que no se pretenda elevarlo al nivel de lo permanente y definitivo. Cuando Camus interpreta entonces el suicidio como la negación del absurdo, procede a valorarlo negativamente. Quien se suicida lo que pretende es introducir un orden final, cerrado y esencial como el que pueda tener la naturaleza o la ciencia, pero perfectamente inhumano por cuanto, a partir de la muerte, desaparece el absurdo que caracteriza y sostiene a la existencia, cesa esa "confrontación desesperada entre la interrogación humana y el silencio del mundo". Luego, el suicidio es el acto inhumano por excelencia, ya que niega la posibilidad de rebelión, tan característica del hombre libre, y supone, por el contrario, un consentimiento, la aceptación de un orden en el límite: "tout est consommé, l'homme rentre dans son histoire essentielle". Podría parafrasearse a Camus diciendo que el suicida comete el acto absurdo de resolver el absurdo. $Y$ es un acto absurdo porque, por definición, el absurdo de la existencia no se resuelve: se vive, se asume, como la mejor expresión de responsabilidad humana. De ahí aquella frase tan curiosamente religiosa de Camus, al insistir en que de lo que se trata es de "morir irreconciliado y no por propia voluntad". Por supuesto que semejante moralismo, no demasiado alejado de las grandes tesis católicas, descansa en una visión absoluta de la muerte: en medio del absurdo, de la no-razón, de la contingencia, de esta suma de abiertas posibilidades que es la existencia, yérguese esa piedra amenazadora y definitiva que es la muerte, opuesta a la libertad humana. El hombre de Camus vive "par opposition à cette constante exception qu'est la mort". Sucede que la muerte y la locura son situaciones-límite, hechos "irremediables", fin de la riqueza movediza y abierta del absurdo. En consecuencia, Camus se torna juez que sentencia al predicar que "mediante el simple juego de la conciencia, transformo en regla de vida lo que era iniciación a la muerte y procedo a rechazar el suicidio". Se está ante otro apóstol de la vida, aunque la exalte bajo la forma del absurdo. Perfectamente coherente (puesto que no se trataba de ningún absurdo lógico), Camus mete en el mismo saco condenatorio al suicidio y al asesinato, expresiones hermanas de la muerte; ambos deben ser rechazados conjuntamente, de tal manera que, en definitiva, aquello de que el suicidio era el gran problema filosófico se reduce a volver a recitar, con toda unción y rigor, el viejo "no matarás". Quien eligiera el absurdo como expresión de "máxima libertad y motor de la humana rebeldía retrocedió ante la posibilidad final de escoger la muerte, y no vaciló en emitir cuanta prohibición de suicidio fuera necesaria. El hombre es libre de todo menos de renunciar a la libertad. Además de llegar así al contrasentido de una libertad obligada, en su afán por rechazar lo esencial y definitivo de toda muerte, Camus termina por esbozar auténticas utoṕas. A suicidio 
$\mathrm{y}$ asesinato hay que rechazarlos en bloque. $O$ tomarlos igualmente en bloque por aquello de que "on n'est pas nihiliste $\grave{a}$ dem $i$ ". Pero no hace falta ser muy ducho en seguir un razonamiento para exigirle a Camus que valga la misma regla a la hora de aceptar su opuesto. Tampoco se puede ser vitalista y optimista a medias. Habrá que aceptar la vida totalmente, sin violencia alguna, sin ninguna falla, como un valor absoluto, en el límite ideal de la más plena y lograda inmortalidad, esto es, justamente lo más alejado del absurdo. Donde es posible ver cómo un rechazo metafísico de la muerte puede conducir a una contradicción existencial y, aún más, a una delirante postulación utópica. Ese amor de Camus por la vida y el desorden, personificado en el absurdo de la libre existencia, es como buen amor total, ciego: no hay vida sin muerte como no se da existencia sin esencia o absurdo sin necesidad. Dentro del ambiente de una cultura católica, mediterránea, tan cara a Camus, $\mathrm{Pa}$ pini fue un poco más sutil. En aquel breve relato, Una morte mentale, en el que pinta el curioso suicidio de Otón Kressler, quien lo logró " $a$ forza di pensare di voler morire", Papini avanza algo más que Camus en la caracterización del trasfondo del suicidio: "no sólo el secreto de la vida está en la muerte, sino que el secreto de la luz está en las tinieblas, el secreto del bien está en el mal y el de la verdad en el error". El de Camus es típicamente existencialista: es un error de elección. Eligió quedarse tan sólo con una parte fingiendo que se puede prescindir del complemento.

Ya es tiempo de darse cuenta de que en Camus la decepción es doble. No sólo escamotea el gran problema filosófico del suicidio haciéndolo desaparecer, sino que ni siquiera intenta la más débil explicación del hecho. Se limita a rechazarlo, a prohibirlo desde el púlpito existencialista del absurdo. Porque decir que el suicidio es la negación de la existencia vuelve a resultar otra triste y vacía tautología como aquella de Freud de que el suicida se mata porque se mata; en el caso de Camus, el suicida se mata porque rechaza la vida. Es una verdad tan innegable cuan útil, pues justamente a partir de ahí es cuando hay que comenzar a hacer preguntas. Para Camus como para Freud, cómodamente, ése es el punto final. De ahí, la frustración que ambos producen.

En una reflexión profunda del hecho del suicidio hay que tomar en cuenta al suicida y al no-suicida, es decir, a quien decide realizar el terrible acto y a quien opta por no hacerlo. Lo que se propone, de entrada, es una neutralidad provisional: tanto importa explicar al suicida como explicar, por similares motivos, al no-suicida.

Imagínese por un momento una humanidad que por determinadas causas genéticas o por razones simplemente políticas desarrollara la muerte voluntaria como regla general a partir de cierta edad: una especie de 
suicidio a término, una sociedad en que "lo natural", esto es, lo estadísticamente establecido, fuera el suicidio a una determinada edad. Como ni siquiera la más desenfrenada utopía (¿distopía, en este caso?) puede ser perfecta, en semejante sociedad, habría también excepciones a la regla: se darían los casos de incumplimiento de la norma: aquellos que no llevaran a cabo el acto de muerte voluntaria; con más propiedad que ahora serían posiblemente llamados "sobrevivientes" y hasta serian perseguidos, controlados y es de creer que estudiados. ¿Por qué no matarse?, ése sería el punto de partida de cualquier estudio en profundidad. No se tardaria mucho, aunque tampoco se avanzaría gran cosa, en establecer que todos los "sobrevivientes" presentan el síndrome del terror a la muerte.

Por ahí se puede comenzar también en el caso de una humanidad que propone la sobrevivencia y rechaza el suicidio. Parte de la clave está en la radical pareja vida/muerte.

Por un lado, el culto a la vida elevado a la categoría de auténtico fetichismo. Por otro lado, el terror a la muerte, expresión del mal, alimentado por la religión. En la concepción judeo-cristiana, la vida como valor supremo ha alcanzado la proyección absoluta de otra inmortalidad a través de la creencia en una vida eterna. Lo que, a su vez, desencadena la paradoja de la muerte redentora y cómplice de esa otra vida: mors ianua vitae. Ése fue el motor que impulsó en su día a los mártires, aunque por lo general ofrece el contraste de su más acendrado rechazo. Pese a todo el esfuerzo metafísico de quienes prueban la inevitabilidad del fin, enraizada en lo del "hombre-ser-para-la-muerte", quien tenía razón era Sartre: actuamos como si no fuéramos a morir jamás. Huxley lo dijo más resignadamente: "death is the only thing we haven't succeeded in completely vulgarising".

Dentro del trasfondo de rechazo a la muerte, el rechazo al suicidio constituye un tipo especial de terror cultural que, en épocas, se igualaba con el terror a los vampiros: a los suicidas se les enterraba en las encrucijadas de caminos, para que su alma errante y condenada se perdiera, y se les clavaba una estaca en el corazón, para que no salieran después de muertos. En el fondo, el miedo que inspira el suicida es similar al miedo que genera todo acto excéntrico: el suicida rompe las reglas de un juego. Lo peor es que es el único que juega, lo tiene que jugar solo y una sola vez. Quizás lo que más terror inspire es la opacidad del suicidio: como la única forma de comprenderlo seria comprender al suicida, y éste, si tiene éxito, ya no está disponible para ningún ejercicio de comprensión, y si no lo tiene queda reducido al estado de enfermo a los ojos de los demás, el acto del suicidio asume así la forma inquietante del enigma absoluto. "Eso es lo difícil del suicidio" - obser- 
vó Pavese, poco antes de ejecutar el suyo-. "Es un acto ambicioso que sólo puede cometerse cuando se ha dejado atrás toda ambición." Pero además es una burla, una trampa, una ruptura del orden, pues de no ser tal, se derrumbaría el mundo para quien se siente sano, normal y con deseos de vivir. Para que el suicida tuviera razón, alguna razón, el resto de la humanidad debería verse desprovista de ella. La consecuencia es el anatema: o criminal o trastornado. Todo suicida muere por partida doble: a la muerte que él mismo se inflige súmase la que le asesta el juicio de los sobrevivientes. $Y$, sin embargo, podría sustentarse una "lógica" del suicidio, ya que si, en efecto, hay otra vida, como la mayoria de las religiones ofrecen, lo más "lógico" sería adelantarse a ir a su encuentro; y si no la hay, como sospecha el prosaico sentido común, la muerte puede ser algo más que un descanso a una existencia molesta e insoportable por tantas razones en más de una ocasión. Sólo que en el plano formal y vacío de lo meramente lógico, toda contra-argumentación es posible. De este modo, si no hay más vida que ésta, la muerte voluntaria es la expresión del más necio de los derroches: perder lo único que se tiene. $Y$ si hubiere otra vida después de la muerte, bien pudiera perderse por el cástigo al suicidio, pecado de soberbia al querer adelantar acontecimientos extra-humanos. En ocasiones, ese recurso al argumento del castigo asumió formas más bien irónicas y barrocas. Durante la conquista de América, en ciertas regiones, los indios preferían suicidarse en masa antes que tener que trabajar como esclavos. El recurso de los conquistadores no pudo ser más teológico, digno del Concilio de Trento: se les aseguró a los indios que también los conquistadores se suicidarían a fin de continuar esclavizándolos en el más allá. L.ograron contener la ola de suicidios masivos $\mathrm{y}$, de paso, constituyeron un antecedente en la campaña de prevención del suicidio y hasta pudiera decirse que se ganó una prueba más: si sólo hay esta vida, o como les gustaba decir a los saduceos españoles, "sólo hay el nascer y el perecer", más vale soportarla, que de haber otra cosa, siempre existe la posibilidad de prolongar ad aeternum el sufrimiento padecido en ésta. Donde vuelve a verse que el suicida pierde de continuo: en su cuerpo y en su razón.

El punto de arranque existencial y humano debería entonces ser ése: considerar al suicida todo lo más como un equivocado, no necesariamente como un enfermo. El hombre ha desarrollado su capacidad represiva hasta el punto de tratar como locos a los disidentes políticos. Quienes tanto se escandalizan por ello, deberían reflexionar sobre el trato que prácticamente en todas partes se da a ese tipo especial de disidentes que son los suicidas, auténticos disidentes existenciales. Al fin y al cabo, su disidencia es con la vida. Otra vez, cierta coherencia lógica pareciera sugerir que o se acepta que se condenen todas las disi- 
dencias o se acepta que se den todas libremente. Dicho con apoyo en Camus: no es posible ser moralista a medias.

En cualquier caso, la oposición existente entre el suicidio considerado como enfermedad y el suicidio visto como plena posibilidad humana viene a ser la vieja antinomia entre destino y libre albedrío. Quienes crean en la predestinación (y ya se sabe en qué latitudes tales creencias predominan) tenderán a ver en todo suicida un marcado de Dios, un ser sujeto a un destino, que se traduce por una enfermedad o trastorno. Mientras que quienes sigan practicando, aun sin saberlo, el culto al libre albedrio de todo hombre serán más receptivos a ver en el suicida el dueño de su propia elección, por terrible y definitiva que ésta sea.

Quizás porque Koestler gozó de extraterritorialidad religiosa respecto de aquella disputa teológica entre predestinación y libertad, pudo escribir en su Testamento español las palabras que mejor resumen esta querella y aun el drama íntimo del suicida en el momento supremo:

Siempre pienso en Sir Peter que me decía que antes de suicidarse con morfina hay que desinfectar bien la aguja para evitar algún absceso. 